\title{
PELATIHAN PENGGUNAAN ALAT UKUR DAN PENGUKURAN BAGI GURU IPA SMP WILAYAH SIDOARJO
}

\author{
Oleh \\ Lydia Rohmawati, Imam Sucahyo, Alimufi Arief, dan Mita Anggaryani ${ }^{*}$
}

\begin{abstract}
Abstrak
Pembelajaran IPA berbasis kurikulum 2013 sangat identik dengan kegiatan pengamatan dan eksperimen. Pada fase pendahuluan, media pembelajaran diperlukan untuk memotivasi siswa. Beberapa alat pengukuran dalam fisika yang sering digunakan dalam kelas, sebagai contoh jangka sorong dan multimeter analog. Berdasarkan pada kegiatan Pengabdian Kepada Masyarakat (PKM) yang didanai oleh BOPTN tahun 2013, pada SMP PGRI 1 Buduran Sidoarjo, sekitar 65\% guru-guru di SMP PGRI Sidoarjo mengalami kesulitan dalam mengajarkan materi alat ukur dan pengukuran di Fisika. Dengan mempertimbangkan hasil PKM sebelumnya, diputuskan untuk mengembangkan media guna membantu proses belajar mengajar dengan membuat poster dari jangka sorong dan multimeter analog. Setelah kegiatan PKM selesai, terdapat beberapa respon terhadap aktivitas PKM. Lebih dari $75 \%$ peserta setuju bahwa poster yang dibuat oleh tim PKM menyajikan kompetensi utama dalam kurikulim 2013 dengan baik dan mengembangkan pengetahuan guru sebagai peserta. Peserta juga memberikan respon bahwa poster tersebut merupakan media kreatif dalam kegiatan belajar mengajar, sederhana tetapi mengandung banyak informasi. Lebih jauh, poster juga memiliki nilai ekonomis. Sekitar $80 \%$ peserta mengatakan bahwa poster sangat membantu dalam kegiatan belajar mengajar. Respon lain yang berhubungan dengan gambar dan performa, 63\% peserta mengatakan bahwa setiap poster memiliki gambar yang jelas dan $60 \%$ peserta mengatakan bahwa poster tersebut sangat menarik.
\end{abstract}

Kata kunci: kurikulum 2013, workshop, alat-alat ukur

\begin{abstract}
Natural sciences learning based on curriculum 2013 was identically conducted thorough observation and experiment activities. As an introduction phase, learning and teaching media are needed to motivate students. Some measurement tools in Physics that are often used in class are for example, vernier callipers and analog multimeter. According to community services or Pengabdian Kepada Masyarakat (PKM) which is funded by BOPTN in 2013, at SMP PGRI 1 Buduran Sidoarjo, it is about 65\% of natural sciences teachers in SMP PGRI Sidoarjo that have difficulty in teaching about measure and measurements in physics. Considering the previous PKM program, it is decided to develop media to help teaching and learning process, the making of poster vernier callipers and analogue multimeter. After the PKM program finished, there are some responses to the PKM activities. More than $75 \%$ participants agree that posters made by PKM team presented the main competency in curriculum 2013 very well and developed the teachers, knowledge, as participants. The participants also respond that the poster is a creative media for teaching and learning, simple but contain numerous information. Moreover, it also has economic value. About $80 \%$ participants said that the poster really has helpful in teaching and learning activity. The other responds related to graphics and performance, $63 \%$ participants said that each poster has a clear picture and $60 \%$ participants said that it has really interesting.
\end{abstract}

Keywords: curriculum 2013, Workshop, Measurement tools

*) Dosen di Jurusan Fisika, Fakultas MIPA, Unesa 


\section{PENDAHULUAN}

Penyelenggaraan pembelajaran IPA yang ideal identik dengan adanya kegiatan ilmiah seperti kegiatan pengamatan dan percobaan atau yang seringkali dikaitkan dengan kegiatan praktikum. Pemberian pengalaman belajar dalam kegiatan merumuskan masalah, mengajukan dan menguji hipotesis melalui percobaan, merancang dan merakit instrumen percobaan, mengumpulkan, mengolah, dan menafsirkan data, serta mengkomunikasikan hasil percobaan secara lisan dan tertulis, dimana diyakini dapat mengembangkan kemampuan bernalar dalam berpikir analisis induktif dan deduktif. Hal ini sesuai dengan misi pembelajaran IPA, yaitu membentuk sikap positif terhadap alam dengan menyadari keteraturan dan keindahan alam, mengagungkan kebesaran Tuhan Yang Maha Esa serta mengembangkan sikap ilmiah yaitu jujur, obyektif, terbuka, ulet, kritis dan dapat bekerjasama dengan orang lain.

Kegiatan praktikum pada umumnya tidak terlepas dari kegiatan pengamatan dan pengukuran. Praktikum IPA, khususnya Fisika, banyak sekali menggunakan alat ukur yang memiliki karakteristik masingmasing yang membutuhkan keterampilan tertentu dari pengguna atau praktikan. Beberapa alat ukur Fisika yang sering digunakan antara lain: jangka sorong, mikrometer sekrup, termometer, neraca pegas, stopwatch, dan multimeter analog. Ketika melakukan pengukuran tidak terlepas dari besaran dan satuan. Selain itu, pengukuran dalam praktikum untuk mendapatkan data dapat dilakukan secara tunggal ataupun berulang. Kedua pengukuran ini tentu saja memiliki taraf ketelitian yang berbeda. Pengetahuan mengenai aturan angka penting dan operasinya, memegang peranan bagaimana data hasil pengukuran disajikan.

Berdasarkan kegiatan PKM Jurusan Fisika Dana BOPTN tahun 2013 di SMP PGRI 1 Buduran, Sidoarjo, diketahui bahwa kurang lebih $65 \%$ dari guru IPA SMP PGRI di bawah MKKS Sidoarjo mengalami kesulitan dalam melakukan pengukuran dengan menggunakan jangka sorong, mikrometer sekrup, dan multimeter analog. Kesulitan ini disebabkan antara lain: 30\% guru yang mengikuti PKM di SMP PGRI 1 Buduran ini bukan guru IPA-Fisika, namun mereka tetap harus mengajar Fisika di sekolah masingmasing, 25\% dari peserta PKM menyatakan kegiatan praktikum IPA lebih banyak mengamati, namun tidak melakukan pengukuran, 20\% peserta menyatakan memang belum bisa menggunakan alat-alat tersebut karena memang tidak pernah menggunakan alat tersebut, $17 \%$ peserta menyatakan tidak punya panduan untuk mengajari siswa mengenai alat ukur dan pengukuran yang benar, 15\% peserta menyatakan alat ukur yang dimiliki sekolah terbatas jumlahnya dan kawatir jika rusak, dan 3\% peserta menyatakan sekolah belum memiliki sarana dan prasarana laboratorium yang lengkap ataupun belum memiliki laboratorium.

Menyikapi hal ini, Tim PKM Jurusan Fisika, merasa perlu untuk melakukan kegiatan pelatihan 
mengenai Alat Ukur dan Pengukuran bagi guru-guru IPA SMP PGRI di Sidoarjo. Kegiatan ini juga merupakan jawaban atas permintaan guru-guru peserta workshop PKM di SMP PGRI 1 Buduran, Sidoarjo tahun lalu. Para guru merasa bahwa keterampilan untuk melakukan pengukuran dan menggunakan alat ukur sangat diperlukan untuk menyiapkan siswa mencapai ranah pengetahuan dan keterampilan secara ilmiah. Hal ini sejalan dengan kurikulum 2013 yang menitikberatkan pada metode keterampilan proses sains.

Adapun kegiatan ini akan memberikan kesempatan bagi para guru IPA untuk meningkatkan kompetensinya dalam usaha membuat pembelajaran yang berkualitas. Peningkatan kompetensi guru Fisika ini diwujudkan dalam kegiatan "Pelatihan Penggunaan Alat Ukur dan Pengukuran Bagi Guru IPA SMP Wilayah Sidoarjo"

\section{METODE PELAKSANAAN}

Kegiatan PKM Pendampingan Pelatihan Penggunaan Alat Ukur dan Pengukuran yang dilaksanakan pada tahun 2014 ini merupakan kegiatan PKM lanjutan yang dilakukan oleh dosen-dosen Jurusan Fisika pada tahun 2013 di SMP PGRI 1 Buduran, Sidoarjo. Adapun kegiatan ini diharapkan dapat menjawab permasalahan yang ditemui oleh guruguru selama melakukan kegiatan praktikum yang melibatkan alat ukur, khususnya alat ukur di dalam praktikum Fisika. Alur dari metode penyelesaian masalah yang diketengahkan oleh Tim PKM adalah sebagai berikut.

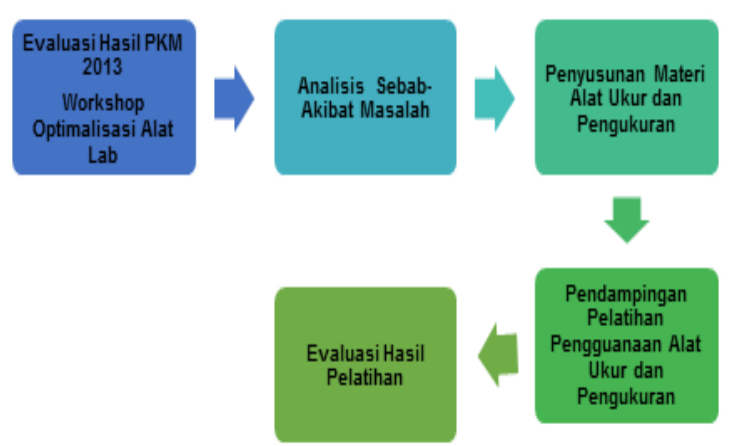

Gambar 1. Diagram Alir Metode Pelaksanaan

\section{Evaluasi Hasil PKM 2013}

Evaluasi hasil PKM 2013 dilaksanakan sebagai bagian dari laporan kegiatan PKM serta identifikasi masalah dan rencana PKM selanjutnya. Evaluasi ini memperhatikan data respon peserta workshop (guru-guru) dan juga hasil observasi selama kegiatan workshop berlangsung.

\section{Analisis Sebab-Akibat Masalah} Analisis sebab-akibat dari masalah yang diidentifikasi dilaksanakan dalam dua kegiatan Focus Group Discussion (FGD). Kegiatan FGD pertama dilaksanakan setelah kegiatan workshop pendampingan penyusunan Lembar Kerja Siswa (LKS) untuk mengoptimalkan penggunaan alat-alat laboratorium berakhir. Kegiatan FGD yang kedua akan dilaksanakan sebagai bagian dari kegiatan sosialisasi PKM Jurusan Fisika tahun 2014. Dengan sasaran kegiatan guru-guru SMP PGRI di Sidoarjo. 


\section{Penyusunan Materi Alat Ukur dan Pengukuran}

Penyusunan materi dilaksanakan setelah FGD kedua dilaksanakan, agar sesuai dengan kebutuhan Guru-guru di lapangan. Materi berupa modul dapat digunakan juga sebagai referensi bahan ajar di sekolah.

\section{Pendampingan}

Alat Ukur dan Penggunaan Alat Ukur dan Pengukuran

Kegiatan disesuakan dengan jadwal yang telah disepakati dalam FGD kedua.

\section{Evaluasi Hasil Pelatihan}

Evaluasi dilaksanakan setelah kegiatan pelatihan selesai. Hasil evaluasi dapat digunakan sebagai referensi kegiatan PKM tahun berikutnya.

\section{HASIL DAN PEMBAHASAN}

Kegiatan PKM diawali dengan mengajukan surat permohonan kerjasama dengan Kepala Diknas Sidoarjo, berupa rekomendasi kegiatan. Hal ini dilakukan agar kegiatan yang dilakukan tepat pada sasaran dan diikuti sepenuhnya oleh para guru yang merupakan perwakilan dari beberapa sekolah di Sidoarjo. Dalam pertemuan tersebut tim PKM memberikan ulasan tentang kegiatan yang akan dilaksanakan, yaitu berkaitan dengan penggunaan alat ukur dan pengukuran yang merupakan solusi dari angket guru pada kegiatan PKM yang telah dilakukan sebelumnya di SMP PGRI Buduran tahun lalu. Pada waktu itu umumnya mereka tidak pernah menggunakan alat ukur secara langsung dikarenakan latar belakang pendidikan guru tidak semuannya dari bidang Fisika. Sehingga dimungkinkan pada saat pembelajaran mereka kesulitan dalam menerapkan alat ukur di Laboratorium IPA, terutama jika dikaitkan dengan kurikulum 2013. Kegiatan PKM ini dilaksanakan di SMP 10 Nopember Sidoarjo, rencananya diikuti oleh 20 peserta dari 10 sekolah. Akan tetapi pada pelaksanaannya hanya diikuti oleh 15 peserta dari 7 sekolah.

Pada saat pelaksanaan kegiatan, pertama yang dilakukan adalah memberikan pengarahan kepada para guru berupa tahapan cara pembuatan poster alat ukur hingga cara pengukuran untuk berbagai skala nonius (Gambar 2). Mereka sangat antusias sekali, karena dengan bahan yang begitu sederhana dapat dijadikan sebuah media yang bernilai jual, bahkan dapat diterapkan langsung saat pembelajaran di kelas atau di Laboratorium IPA.

Pendapat Bapak/lbu peserta PKM setelah mendapatkan materi pembuatan poster alat ukur dan pengukurannya secara umum sangat positif (Tabel 1). Dalam aspek materi, $78 \%$ peserta menyatakan poster yang dibuat sangat sesuai dengan Kompetensi Inti, Kompetensi Dasar dan memberikan pengetahuan baru. Dalam aspek penyajian, $75 \%$ peserta menyatakan bahwa poster yang dibuat sangat kreatif, sederhana dengan cakupan informasi yang luas, dan disusun secara logis, sistematis serta biaya yang dibutuhkan dalam pembuatannya sangat terjangkau. 
Pada aspek keterlaksanaan, $80 \%$ peserta menyatakan bahwa media poster dapat membantu guru dalam menjalankan proses pembelajaran dan sangat mudah untuk digunakan. Untuk aspek gambar, $63 \%$ peserta menyatakan bahwa gambar yang ada pada poster sangat jelas dan sangat terkait antara gambar dan materi. Aspek kegrafikan/tampilan, 60\% peserta menyatakan bahwa tampilan fisik poster sangat menarik dan ukuran poster yang dibuat sangat sesuai dengan kebutuhan pembelajaran.

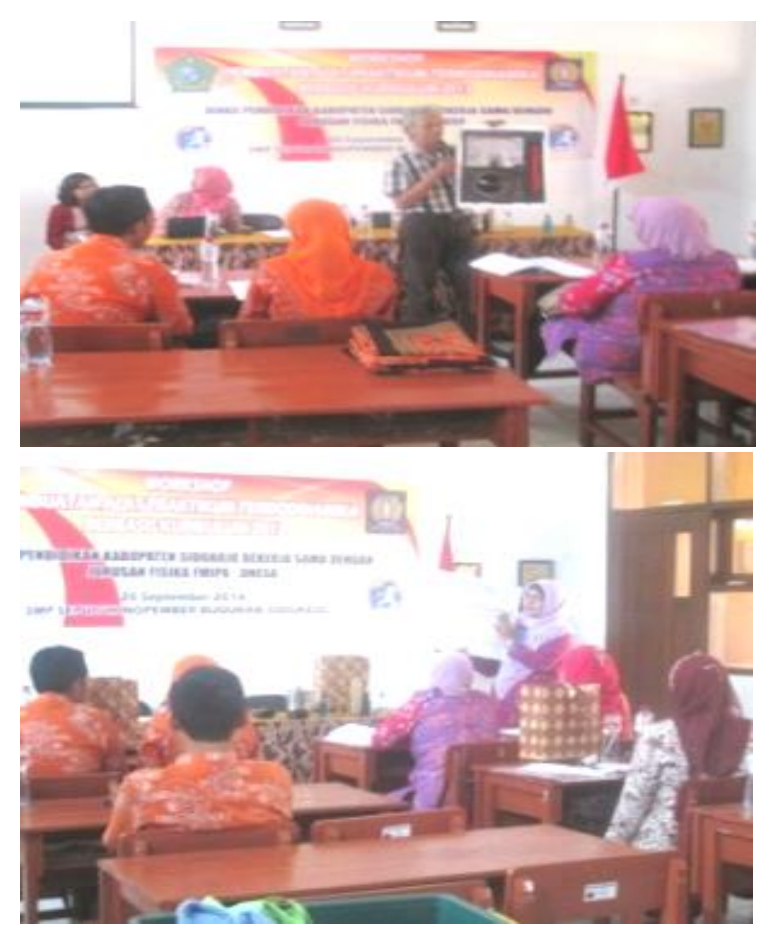

Gambar 2. Pengarahan Pembuatan Poster Alat Ukur

Tabel 1. Respon Peserta Terhadap Materi PKM

\begin{tabular}{|c|c|c|c|c|c|}
\hline \multirow[b]{2}{*}{ No. } & \multirow[b]{2}{*}{$\begin{array}{l}\text { Aspek } \\
\text { Penilaian }\end{array}$} & \multirow[b]{2}{*}{ Indikator } & \multicolumn{3}{|c|}{ Persentasi (\%) } \\
\hline & & & $\begin{array}{l}\text { Sangat } \\
\text { Baik }\end{array}$ & Baik & Kurang \\
\hline \multirow[t]{3}{*}{1.} & \multirow[t]{3}{*}{ Materi } & $\begin{array}{l}\text { Kesesuaian materi dalam poster } \\
\text { dengan Kompetensi Inti }\end{array}$ & \multirow[t]{3}{*}{78} & \multirow[t]{3}{*}{22} & \multirow[t]{3}{*}{0} \\
\hline & & $\begin{array}{l}\text { Kesesuaian materi dalam poster } \\
\text { dengan Kompetensi Dasar }\end{array}$ & & & \\
\hline & & $\begin{array}{l}\text { Materi dalam poster memberikan } \\
\text { pengetahuan baru }\end{array}$ & & & \\
\hline \multirow[t]{4}{*}{2.} & \multirow[t]{4}{*}{ Penyajian } & $\begin{array}{l}\text { Penyajian poster secara sederhana } \\
\text { dengan cakupan informasi yang luas }\end{array}$ & \multirow[t]{4}{*}{75} & \multirow[t]{4}{*}{23} & \multirow[t]{4}{*}{2} \\
\hline & & $\begin{array}{l}\text { Penyajian materi dalam poster } \\
\text { disusun secara logis dan sistematis }\end{array}$ & & & \\
\hline & & $\begin{array}{l}\text { Poster yang disajikan } \\
\text { membutuhkan biaya yang } \\
\text { terjangkau dalam pembuatannya }\end{array}$ & & & \\
\hline & & Kreativitas dalam pembuatan poster & & & \\
\hline \multirow[t]{2}{*}{3.} & \multirow[t]{2}{*}{ Keterlaksanaan } & Kemudahan poster saat digunakan & \multirow[t]{2}{*}{80} & \multirow[t]{2}{*}{20} & \multirow[t]{2}{*}{0} \\
\hline & & $\begin{array}{l}\text { Media poster dapat membantu guru } \\
\text { dalam menjalankan proses } \\
\text { pembelajaran }\end{array}$ & & & \\
\hline \multirow[t]{2}{*}{4.} & \multirow[t]{2}{*}{ Gambar } & Kejelasan gambar yang digunakan & \multirow[t]{2}{*}{63} & \multirow[t]{2}{*}{34} & \multirow[t]{2}{*}{3} \\
\hline & & $\begin{array}{l}\text { Kesesuaian antara gambar dengan } \\
\text { materi terkait }\end{array}$ & & & \\
\hline \multirow[t]{2}{*}{5.} & \multirow[t]{2}{*}{$\begin{array}{l}\text { Kegrafikan/ } \\
\text { tampilan }\end{array}$} & $\begin{array}{l}\text { Ukuran poster yang dibuat sesuai } \\
\text { dengan kebutuhan pembelajaran }\end{array}$ & \multirow[t]{2}{*}{60} & \multirow[t]{2}{*}{37} & \multirow[t]{2}{*}{3} \\
\hline & & Tampilan fisik poster menarik & & & \\
\hline
\end{tabular}


Berdasarkan Tabel 1 di atas menunjukkan bahwa secara umum peserta PKM menyatakan bahwa poster tentang alat ukur sangat mudah digunakan, misalnya pada jangka sorong, cukup dengan menggesergeserkan skala noniusnya. Untuk multimeter analog hanya memutar skrup penunjuk skala, dapat dibaca besar penunjukkanya (dalam satuan Ampere, Volt, ataupun Ohm). Dengan adanya kemudahan dalam penggunaan tersebut, poster juga sangat membantu guru dalam menjalankan proses pembelajaran kegiatan awal dapat digunakan sebagai motivasi siswa, dan kegiatan inti dapat digunakan untuk diskusi. Selain itu materi yang tertuang pada poster juga sudah sangat mencakup kompeteni inti, dasar dan memberikan pengetahuan baru bagi guru maupun siswa. Hal ini materinya sangat sesuai dengan kurikulum 2013, yaitu mengamati, menanya, menganalisis, mempresentasikan, dan menyimpulkan. Adapun saran dan komentar dari Bapak/lbu peserta PKM diantaranya adalah mereka menginginkan kegiatan ini dilakukan secara kontinyu dan berkala dengan materi lain seperti Listrik dan Mekanika. Semua tim PKM sangat antusias sekali dalam pelaksanaan kegiatan PKM, mulai dari awal pembuatan proposal, pengajuan rekomendasi ke Kepala Diknas Sidoarjo, persiapan dan pembuatan media pembelajaran berupa poster tiga dimensi hingga pelaksanaan kegiatan PKM di SMP Sepuluh Nopember Sidoarjo.

\section{SIMPULAN DAN SARAN}

Kegiatan PKM dalam pembuatan alat ukur dan pengukuran bagi guru IPA SMP wilayah Sidoarjo terlaksana dengan baik, dan mendapat respon positif dari guru sebagai peserta. Kebutuhan guru-guru dalam menjalankan proses pembelajaran telah terpenuhi dengan adanya media pembelajaran berupa poster alat ukur dan cara pengukurannya, sehingga alat-alat Laboratorium IPA yang tersedia dapat digunakan dengan sebaik-baiknya.

\section{DAFTAR PUSTAKA}

Asnawi. 2011. Handout Alat Ukur dan Pengukuran. Jurusan Fisika. Fakultas Matematika dan IImu Pengetahuan Alam. Universitas Negeri Surabaya. Surabaya.

Bell, Stephani. 2001. Measurement Good Practice Guide: A Beginner's Guide to Uncertainty of Measurement. National Physical Laboratory. UK

Flack, David. 2001. Measurement Good Practice Guide: Callipers and Micrometers. National Physical Laboratory. UK

NN. ----. Modul Alat Ukur dan Pengukuran.

Tim Fisika Dasar. 2013. Panduan Praktikum Fisika Dasar 1. Universitas Negeri Surabaya. Surabaya.

http://www.slideshare.net/rhizqianacliq uers/makalah-jangka-sorong-dan- 
$\underline{\text { mikrometer (diakses tanggal } 30}$ April 2014)

http://edu.anashir.com/2013/11/alatukur-panjang-mistar-jangkasorong.html (diakses tanggal 30 April 2014)

http://listrikwiber.files.wordpress.com/2 008/09/awalmodul17.pdf (diakses tanggal 30 April 2014)
http://id.wikipedia.org/wiki/Mikrometer (diakses tanggal 30 April 2014)

http://jeperis.wordpress.com/2013/11/1 3/pembelajaran-ipa-padakurikulum-2013/ (diakses tanggal 30 April 2014) 